\title{
Symptoms of burnout in intensive care unit specialists facing the COVID-19 outbreak
}

\author{
Elie Azoulay ${ }^{1 *}$ (D) Jan De Waele ${ }^{2}$, Ricard Ferrer ${ }^{3,4}$, Thomas Staudinger ${ }^{5}$, Marta Borkowska ${ }^{2}$, Pedro Povoa ${ }^{6,7}$, \\ Katerina Iliopoulou ${ }^{8}$, Antonio Artigas ${ }^{9}$, Stefan J. Schaller ${ }^{10}$, Manu Shankar Hari ${ }^{11,12}$, Mariangela Pellegrini ${ }^{13}$, \\ Michael Darmon ${ }^{1}$, Jozef Kesecioglu ${ }^{14}$ and Maurizio Cecconi ${ }^{15}$ On behalf of ESICM
}

\begin{abstract}
Background: The COVID-19 pandemic has resulted in an unprecedented healthcare crisis with a high prevalence of psychological distress in healthcare providers. We sought to document the prevalence of burnout syndrome amongst intensivists facing the COVID-19 outbreak.

Methods: Cross-sectional survey among intensivists part of the European Society of Intensive Care Medicine. Symptoms of severe burnout, anxiety and depression were collected. Factors independently associated with severe burnout were assessed using Cox model.

Results: Response rate was 20\% (1001 completed questionnaires were returned, 45 years [39-53], 34\% women, from 85 countries, 12 regions, $50 \%$ university-affiliated hospitals). The prevalence of symptoms of anxiety and depression or severe burnout was $46.5 \%, 30.2 \%$, and $51 \%$, respectively, and varied significantly across regions. Rating of the relationship between intensivists and other ICU stakeholders differed significantly according to the presence of anxiety, depression, or burnout. Similar figures were reported for their rating of the ethical climate or the quality of the decision-making. Factors independently associated with anxiety were female gender (HR 1.85 [1.33-2.55]), working in a university-affiliated hospital (HR 0.58 [0.42-0.80]), living in a city of $>1$ million inhabitants (HR 1.40 [1.01-1.94]), and clinician's rating of the ethical climate (HR 0.83 [0.77-0.90]). Independent determinants of depression included female gender (HR 1.63 [1.15-2.31]) and clinician's rating of the ethical climate (HR 0.84 [0.78-0.92]). Factors independently associated with symptoms of severe burnout included age (HR 0.98/year [0.97-0.99]) and clinician's rating of the ethical climate (HR 0.76 [0.69-0.82]).
\end{abstract}

Conclusions: The COVID-19 pandemic has had an overwhelming psychological impact on intensivists. Follow-up, and management are warranted to assess long-term psychological outcomes and alleviate the psychological burden of the pandemic on frontline personnel.

Keywords: Coronavirus, Pneumonia, Acute respiratory distress syndrome, Exhaustion, Depersonalization, Well-being

\section{Introduction}

With more than six million confirmed cases worldwide and more than 350,000 deaths between February and May 2020, the COVID-19 pandemic has emerged as an unprecedented healthcare crisis [1-3]. Increasing work

\footnotetext{
*Correspondence: elie.azoulay@aphp.fr

${ }^{1}$ Médecine Intensive et Réanimation, PHP, Hôpital Saint-Louis, Paris University, Paris, France

Full list of author information is available at the end of the article
}

demands on healthcare professionals cause psychological stress. Previous pandemics involving quarantine have emphasized that healthcare workers might develop symptoms of post-traumatic stress disorder, anxiety, depression, insomnia, and substance use disorders [4]. As the spread and burden of the pandemic varied by geographic regions (https://www.who.int/chp/about/regio ns/en), with overwhelming numbers of severe cases in some places [5], and only sporadic transmission with few

\section{Springer Open}

(c) The Author(s) 2020. This article is licensed under a Creative Commons Attribution 4.0 International License, which permits use, sharing, adaptation, distribution and reproduction in any medium or format, as long as you give appropriate credit to the original author(s) and the source, provide a link to the Creative Commons licence, and indicate if changes were made. The images or other third party material in this article are included in the article's Creative Commons licence, unless indicated otherwise in a credit line to the material. If material is not included in the article's Creative Commons licence and your intended use is not permitted by statutory regulation or exceeds the permitted use, you will need to obtain permission directly from the copyright holder. To view a copy of this licence, visit http://creativeco mmons.org/licenses/by/4.0/. 
in others suggesting that the psychological burden also varies across regions [6].

Preliminary reports from countries affected early on in the pandemic highlight the high prevalence of psychological burden in healthcare providers outside the critical care setting $[7,8]$. First, in the general population exposed to the health crisis and state of emergency, high levels of loneliness, worry, fatigue, and low distress tolerance were reported during the early weeks of the COVID-19 pandemic. They were significantly associated with depression, anxiety, and stress symptoms [4, 9]. Second, this psychological burden appears to be higher in healthcare providers, especially in those who are younger, less experienced, and amongst those working in frontline [10]. Increased working hours, the number of Covid-19 patients cared for, and limited logistic support are associated with the highest prevalence of mental burden [10]. In a systematic review of 13 studies $(33,062$ participants), the pooled prevalence of anxiety and depression was $23.2 \%$, and $22.8 \%$, respectively [11]. In a study of healthcare providers exposed to COVID-19 patients, half of them self-perceived burnout [12]. In another study of 376 healthcare professionals in Italy, more than 1 out of 3 showed a high score of emotional exhaustion, and 1 out of 4 reported high levels of depersonalization, while around 15\% reported low levels of personal accomplishment [13]. However, not all these studies captured the three major burnout domains, namely, emotional exhaustion, depersonalization, and personal accomplishment $[14,15]$, using valid instruments.

It is well recognized that the COVID-19 pandemic is putting healthcare professionals working in critical care under extreme pressure [7, 16]. Aside from the disruption of healthcare delivery in highly affected regions, the scarcity of resources such as personal protective equipment, ICU beds, and ventilators, increase this psychological burden [17]. Although features such as exhaustion, psychological disturbances, and stigmatization are to be expected, they are seldom documented [18]. Notably, the prevalence of burnout using a validated screening tool has never been reported in healthcare professionals working in critical care. In this context, to document the prevalence of mental health outcomes in ICU specialists facing the COVID-19 outbreak, we performed an online survey on behalf of the European Society of Intensive Care Medicine (ESICM).

\section{Methods}

This web-based survey endorsed by ESICM collected data between April 30 and May 25, 2020, using an online questionnaire sent through the ESICM members' list (https://www.surveymonkey.com/r/F2FFC6S). Online consent was obtained from the participants.
We collected demographic variables and information regarding personal and professional experience in managing severe COVID-19 patients. The number of COVID19 patients managed as defined as the number of patients for whom the responding physician was providing direct care (clinical examination, medical prescription or procedures during day or night shifts). We collected data on the mental health outcomes included symptoms of severe burnout, anxiety, and depression, using the Hospital Anxiety and Depression Scale (HADS) and Maslach Burnout Inventory (MBI). The HADS is a 14-item auto questionnaire that includes 7 items about symptoms of anxiety, and 7 items on depression [19]. MBI consists of a 22-item questionnaire on the three components of burnout: emotional exhaustion (9 items), depersonalization (5 items), and personal achievement (8 items). Participants were classified as having symptoms of anxiety or depression when the corresponding subscale was $>7$ [20] and high levels of burnout when the MBI was $>-9$ [15]. Visual analog scales were used by respondents to rank their relationship with ICU physicians, nurses, administrators, the quality of the decision-making and the ethical climate. The ethical climate was defined as "individual perceptions of the organization that influences attitudes and behaviour and serves as a reference for employee behavior" [21].

As ESICM has members worldwide, we summarized the demographic characteristics and categorized the respondents from 85 countries, into 12 different regions, as previously described [22]. Continuous variables are described as median (interquartile range [IQR]) and are compared between groups using the non-parametric Wilcoxon rank-sum test. Categorical variables are expressed as frequency (percentages) and are compared between groups using Fisher's exact test. Factors independently associated with mental health outcomes were assessed using Cox model. Conditional stepwise variable selection was performed with 0.2 as the critical $P$-value for entry into the model, and 0.1 as the $P$-value for removal. Interactions and correlations between the explanatory variables were carefully checked. Statistical analyses were performed with $\mathrm{R}$ statistical software, version 3.4.3 (available online at http://www.r-project.org/). A $P$-value $<0.05$ was considered significant.

\section{Results}

Among ESICM members, 5660 opened the e-mail advertising for the survey, 1132 (20\%) responded, including 1001 complete answers for demographic questions (Table 1), 848 complete responses for the Hospital Anxiety and Depression Scale (HADS) and 846 complete responses for the Maslach Burnout Inventory (MBI). 
Table 1 Characteristics of responding physicians

\begin{tabular}{ll}
\hline $\begin{array}{l}\text { Numbers (\%) or median (interquartile } \\
\text { ranges) }\end{array}$ & Total, 1001 respondents \\
\hline Age & $45(39-53)$ \\
Female gender & $342(34.2 \%)$ \\
Single & $170(17 \%)$ \\
Number of children & $2(0-2)$ \\
Religiosity (0 not at all-100 very religious) & $26(1-61)$ \\
Current smoker & $97(9.7 \%)$ \\
Sleeping pills intake & $374(37.4 \%)$ \\
Excessive alcohol intake (self-report) & $121(12.1 \%)$ \\
Live in a city >1 million inhabitants & $403(40.3 \%)$ \\
Work in a university-affiliated hospital & $551(55.1 \%)$ \\
Number of ICU beds baseline/during the & $20(11-36) / 35(20-60)$ \\
surge & $5(3-6)$ \\
Number of night shifts per month & $30(14-60)$ \\
Number of COVID-19 patients managed & \\
Ratings (0 poor-10 excellent) & $8(7-9)$ \\
Relationship with doctors & $9(8-9)$ \\
Relationship with nurses & $7(5-8)$ \\
Relationship with administrators & $8(7-9)$ \\
Relationship with referring physicians & $8(7-9)$ \\
Quality of the decision-making & $8(7-9)$ \\
Ethical climate & \\
Mental health outcomes & \\
Hospital anxiety and depression scale, anxi- & $7(4-9)$ \\
ety subscale & \\
Presence of symptoms of anxiety & $35(29-40)$ \\
Hospital anxiety and depression scale, & $4(2-7)$ \\
depression subscale & $256(30.2 \%)$ \\
Maslach burnout inventory & $-8(-21$ to 8$)$ \\
Presence of severe burnout & \\
Emotional exhaustion sub score & \\
Depersonalization sub score & \\
Personal accomplishment sub score & \\
\hline
\end{tabular}

Respondents (45 years [39-53], 34\% female) were mostly from Middle Europe (25\%), Southern Europe (23\%), the United Kingdom (12\%), South America (9\%), Northern Europe (8.1\%), Eastern Europe (5.3\%), Middle-East (5\%), North America (4.7\%), Asia (3.3\%), India (2.7\%), Australia-New Zealand (1.3\%) or Africa (0.6\%); $54 \%$ were living in a city of $>1$ million inhabitants, and $55 \%$ were working in a University-affiliated hospital. $37.2 \%$ intensivists took sleeping pills, $12 \%$ reported having excessive alcohol intake, and $9.7 \%$ were smoking.

Regarding the mental health outcomes of ICU specialists during the COVID-19 outbreak, the prevalence of symptoms of anxiety, depression, and severe burnout were $46.5 \%, 30.2 \%$, and $51 \%$, respectively (Fig. 1). Ranking (VAS from 0 [poor] to 10 [excellent]) of the

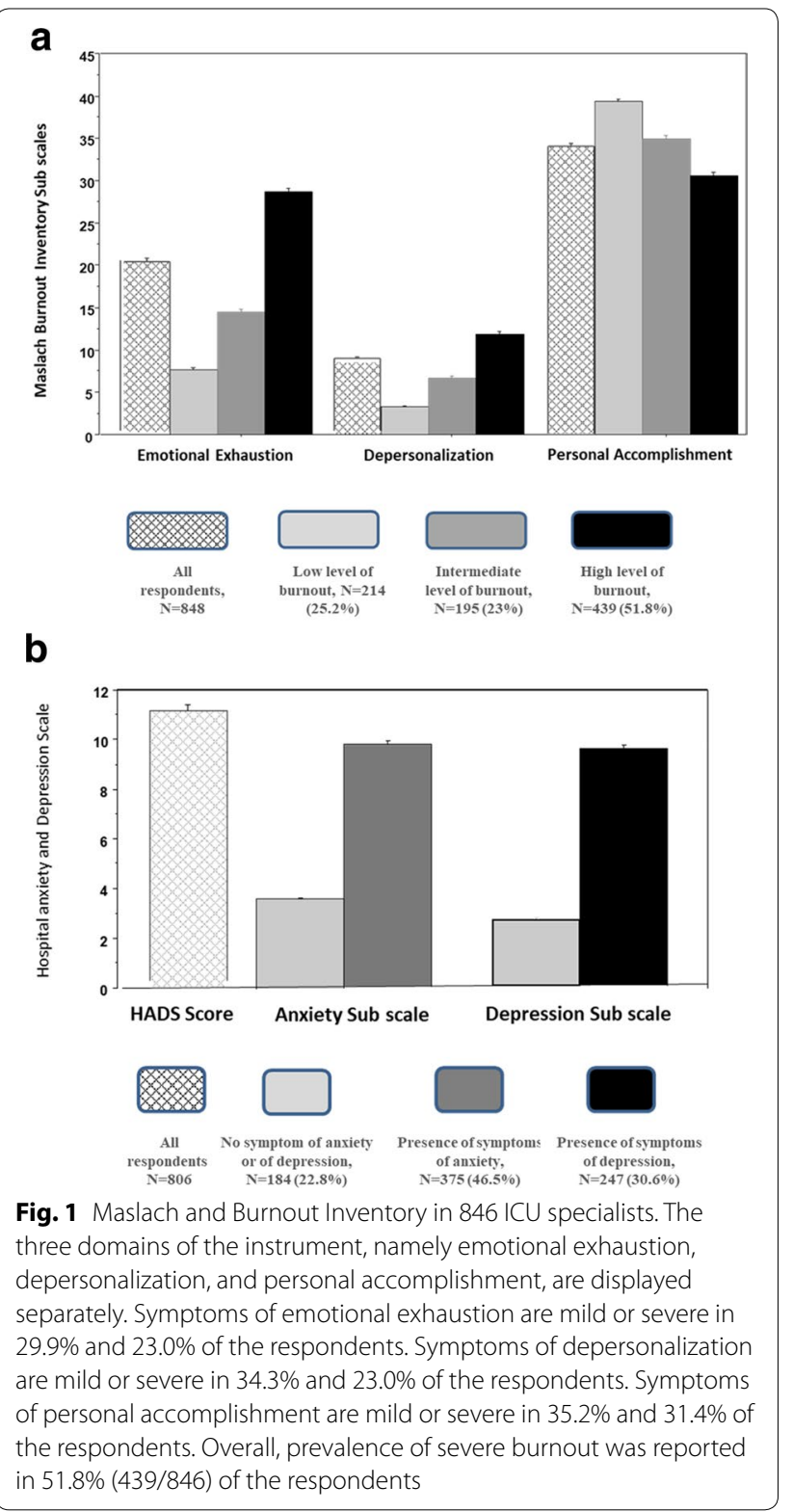

relationship between ICU specialists and other ICU specialists, nurses, administrators, or primary physicians were significantly different according to the presence of

Fig. 2 Physician's ranking (from 0 [very poor relationship] to 10 [excellent relationship]) of their relationship with other ICU specialists, nurses, administrators, or with referring physicians. They have also ranked the quality of the decision-making and the ethical climate in their ICU. Results are presented according to the presence of symptoms of anxiety (a), the presence of symptoms of depression (b), or the presence of symptoms of severe burnout (c). This figure displays the results in the $848 \mathrm{ICU}$ specialists returning complete HADS. ${ }^{* * *}$ indicates $P$ value $<0.0001$ 

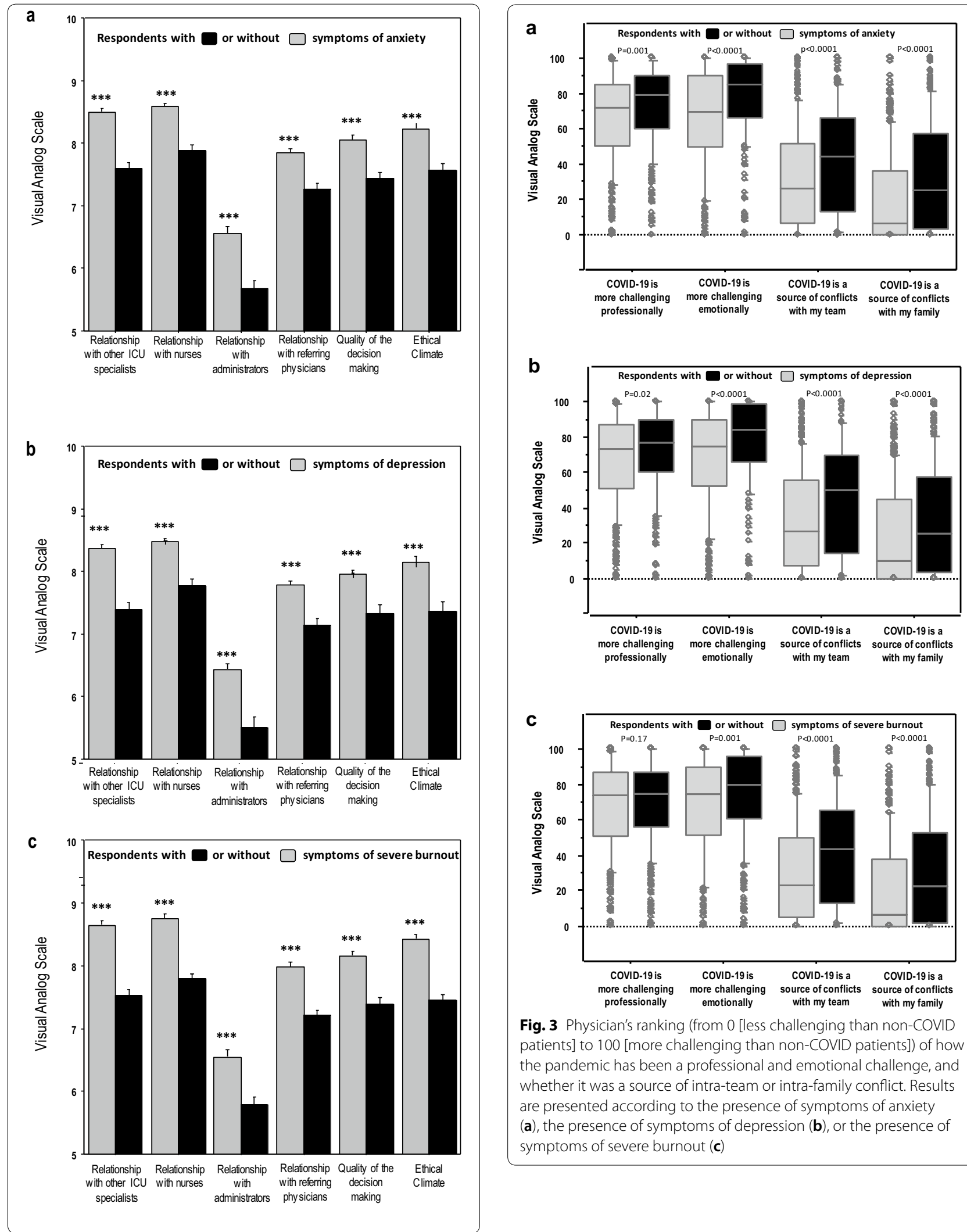

Fig. 3 Physician's ranking (from 0 [less challenging than non-COVID patients] to 100 [more challenging than non-COVID patients]) of how the pandemic has been a professional and emotional challenge, and whether it was a source of intra-team or intra-family conflict. Results are presented according to the presence of symptoms of anxiety (a), the presence of symptoms of depression (b), or the presence of symptoms of severe burnout (c) 


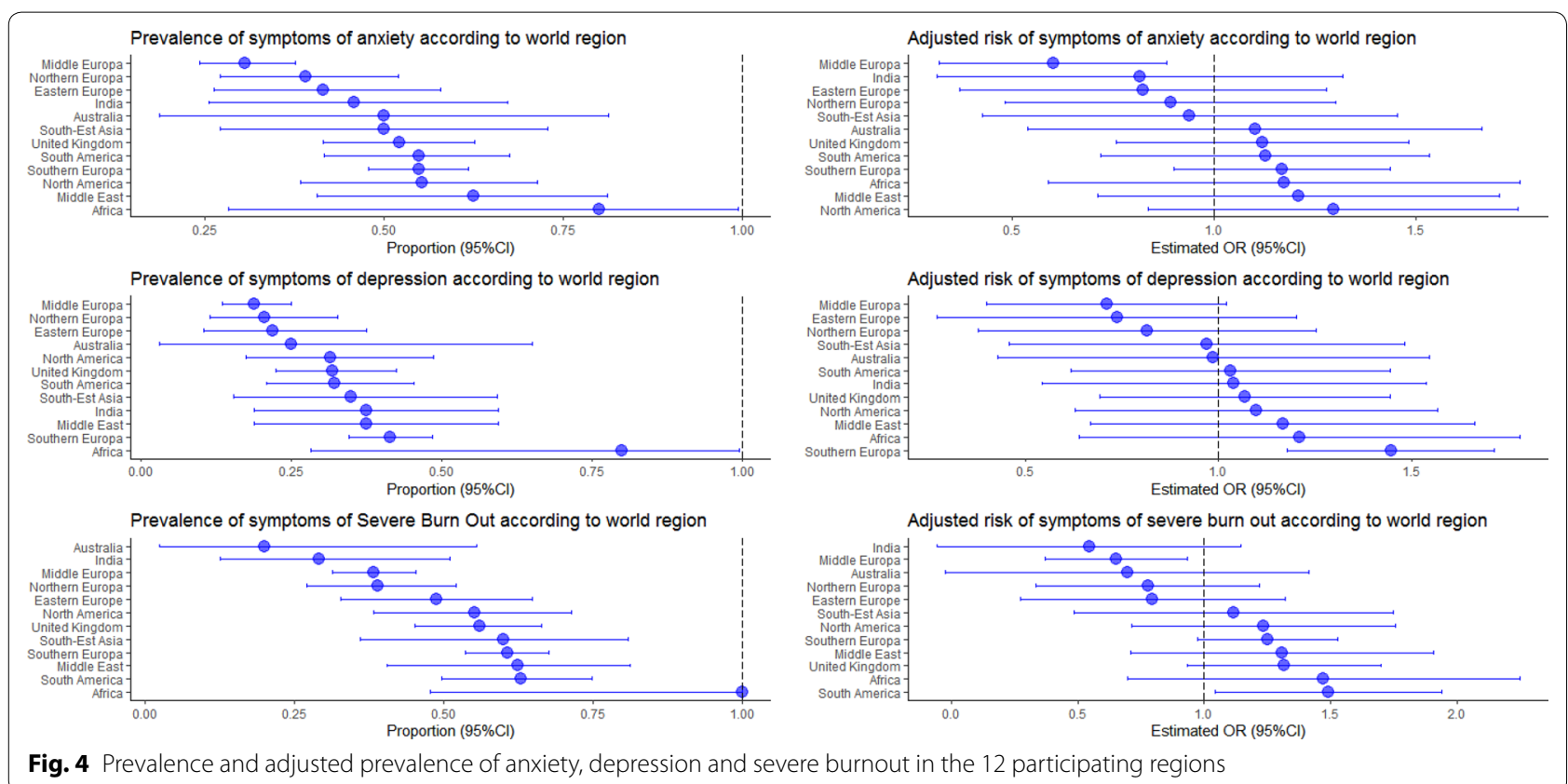

Fig. 4 Prevalence and adjusted prevalence of anxiety, depression and severe burnout in the 12 participating regions

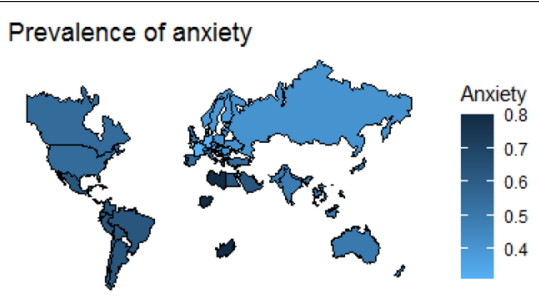

Prevalence of depression

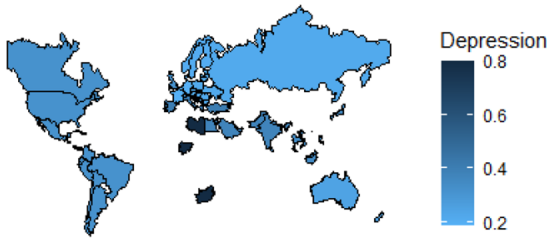

Prevalence of Severe Burn Out

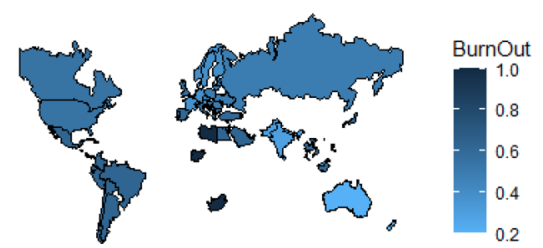

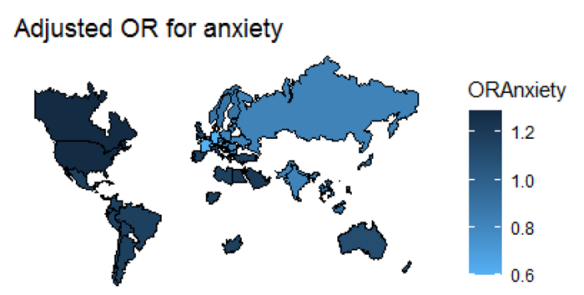

Adjusted OR for depression

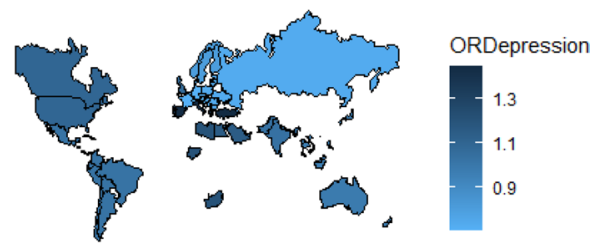

Adjusted OR for Severe Burn Out

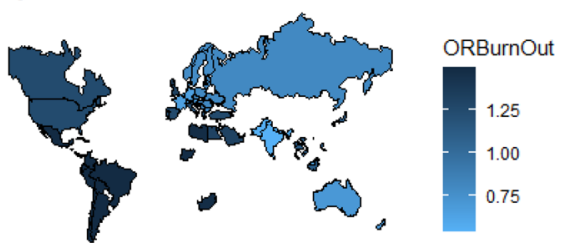

Fig. 5 World map displaying the prevalence (graphs in the left) and the adjusted odds ratio (OR, graphs in the right) of symptom of anxiety, depression and severe burnout across regions

symptoms of anxiety (Fig. 2, panel a), depression (Fig. 2; panel b) or severe burnout (Fig. 2, panel c). Similarly, physicians with either of these symptoms provided significantly lower scores to the ethical climate or the quality of the decision-making ratings (Fig. 2).
Respondents were asked to compare their COVID-19 experience to general ICU non-COVID patients in a 0 (less challenging than non-COVID patients) to 100 (more challenging than non-COVID patients) scale. Overall, the scores reported were $(75$ [55-88]) for the professional 
challenge, (80 [59-93]) for the emotional challenge, (32 [8-61]) for the intra-team conflicts, and (12 [0-50]) for the intra-family conflicts. To the question of whether this experience would make them see their professional career differently, ICU specialists provided a score of 50 (4-75). Figure 3 shows the distribution of the scores in ICU specialists with and without symptoms of anxiety (panel a), depression (panel b), or severe burnout (panel c).

By univariable analysis, factors associated with symptoms of anxiety were female gender $(41.2 \%$ in those with symptoms of depression vs. $27.9 \%$ in those without), younger age (44.5 [38-52] vs. 47 [40-54], years $P=0.0002)$, living in city of $>1$ million inhabitants $(50.2 \%$ vs. $42.1 \%, P=0.02$ ), and higher religiosity (35 [4-66] vs. 19 [0-57], $P=0.001)$. Factors associated with the prevalence of symptoms of depression were female gender (42.4\% in those with symptoms of depression vs. $30.5 \%$ in those without, $P=0.0008)$, younger age ((44 [38-51] vs. 46 [39-54], $P=0.004)$, being single $(21.4 \%$ vs. $15.1 \%$, $P=0.03)$, living in city of $>1$ million inhabitants $(63.6 \%$ vs. $49.5 \%, P=0.0003$ ), and higher religiosity (36 [5-67] vs. $21[0-59], \mathrm{P}=0.002)$. Working in a university-affiliated hospital was associated with a lower prevalence of symptoms of anxiety ( $42 \%$ vs. $52 \%, P=0.007$ ) but did not affect the prevalence of symptoms of depression. Age and female gender were also associated with a higher prevalence of severe burnout (45 [37-51] vs. 47 years [40-55], $P=0.0001$, and $38.2 \%$ vs. $30.1 \%, P=0.02$ ). Clinicians with symptoms of anxiety, depression, or severe burnout were more frequently smoking or taking sleeping pills, whereas alcohol consumption was not affected. The number of COVID-19 patients managed was not associated with the prevalence of the psychological burden.

The prevalence of symptoms of anxiety, depression, and burnout varied significantly across regions (Figs. 4 and 5). For anxiety, Middle Europe, East Europe, Asia, and Scandinavia were in the $30-40 \%$ range, Australia-New Zealand, South America, North America, the UK, and South Europe in the 50-60\%, and India, Middle-East and Africa in the $>60 \%$ range. For depression, Middle Europe, Australia-New Zealand, Scandinavia, and East Europe were in the $20-40 \%$ range, the UK, North America, Asia, South America South Europe, and the Middle East in the $30-50 \%$, and Africa was $80 \%$. For severe burnout, Australia-New Zealand, India, Middle Europe, and Scandinavia were in the $20-40 \%$ range, East Europe, North America, Asia, South America, the UK, South Europe, and the Middle East were in the $50-70 \%$ range.

By multivariable analysis, factors independently associated with symptoms of anxiety were female gender (HR 1.85 [1.33-2.55]), working in a university-affiliated hospital (HR 0.58 [0.42-0.80]), living in a city of $>1$ million inhabitants (HR 1.40 [1.01-1.94]), and clinician's rating about the ethical climate (HR 0.83 [0.77-0.90]). Factors independently associated with symptoms of depression were female gender (HR 1.63 [1.15-2.31]) and clinician's rating about the ethical climate (HR 0.84 [0.78-0.92]). Factors independently associated with symptoms of severe burnout included age (HR 0.98/year [0.97-0.99]) and clinician's rating about the ethical climate (HR 0.76 [0.69-0.82]).

\section{Discussion}

The novel SARS-CoV-2 pandemic has resulted in an overall surge in new cases of anxiety, depression and burnout in critical care health care workers. Determinants of mental health outcomes included clinician's characteristics (age, gender, religiosity), ICU characteristics (region, located in a large city, universityaffiliated), and how critical care specialists ranked the ethical climate in their ICU.

Given the highly contagious nature of SARS-CoV-2, occupational hazards have been associated with more emotional impact in physicians who work on the frontline [10]. However, this study, including ICU specialists managing critically ill COVID-19 patients, did not confirm that exposure to the disease or the physical strain associated with the surge were the leading factors for symptoms of severe burnout, anxiety, and depression $[10,12,13]$. The number of COVID-19 patients managed, the number of night shifts per month, or time since the last vacation at the time of the surge were not associated with either symptom.

The substantial variation in the prevalence of burnout across regions calls for attention [23]. Indeed, the pandemic exposed ICU specialists to the inadequacy of national stockpiles in personal protective equipment, ventilators, staff, and drugs [24-26]. National responses, including lockdown timing and duration, have varied also worsening the psychological pressure on the personnel. Moreover, the lack of established policies for patient's triage and management has increased the burden on health care workers [27]. Each professional society has issued guidelines potentially mismatching with local procedures or with recommendations from other specialties, with no effort to align such guidelines. Last, as the pandemic occurred heterogeneously and asynchronously throughout the world, both the COVID-19 burden and the effects of the lockdown were captured at different time points from the disease peak [4].

Even though anxiety and depression have not been assessed using the HADS, this study reports a prevalence of burnout in ICU physicians of $52 \%$. These results suggest then that the SARS-CoV-2 pandemic has generated more burnout than what could have been expected. For 
instance, in the systematic review from van Mol et al. [28], reported rates of burnout in ICU physicians were about 30\% when the MBI was used [29-32].

Moral distress from suboptimal decision-making, difficulties in involving the relatives, and the perception of inappropriate care may be a cornerstone for the development of psychological burden in ICU specialists. Moral distress is an ethical root cause of clinician burnout [21], translating in low clinician well-being, job dissatisfaction, and job turnover [33]. During the pandemic, tough decisions for patients lacking decision-making capacity had to be made without any relative [34]. Clinicians struggled to balance substituted judgment with their views on the best interests of the patient, creating a climate for suboptimal decision-making [35]. In this study, the quality of the decision-making was associated with the prevalence of symptoms of anxiety, depression, and burnout. Ethical climate should also be recognized as an essential contributor that either alleviates or exacerbates moral distress [33]. Here again, the ranking of ethical climate was an independent predictor of anxiety, depression, and severe burnout. However, studies are needed to ascertain whether the ethical climate could be a surrogate of optimal teamwork in the setting of the COVID-19 pandemic where many difficult decisions were also made in the ED or the wards.

This study has several limitations. First, as an online study with a $20 \%$ response rate, these results might appear as biased. However, burnout syndrome has not been assessed in the setting of the COVID-19 pandemic. Moreover, with 1001 respondents from 85 countries and 12 regions, this is among the most extensive studies assessing severe burnout in ICU healthcare workers and intensivists. Second, the survey focused on frontline clinicians managing the COVID-19 pandemic, with no control group of COVID-19 naïve physicians. As the study was embedded in a COVID-19 survey, clinicians working in places not involved in the pandemic have considered themselves as non-concerned by the subject. However, the lack of association between the number of COVID-19 patients managed and the psychological burden suggests that other non-professional factors contributed to the mental alterations. Third, as half the respondents were from university-affiliated hospitals, a selection bias should be considered. Fourth, the data could not be captured when all of the participating countries were at the peak of the pandemic. Psychological symptoms may vary over time and this could explain part of the regional variability. Last, the restriction of this study to ICU physicians only provides only a partial picture of what post-COVID-19 psychological burden is. Studies assessing mental health outcomes in relation with the pandemic and including all healthcare professionals are warranted.

In summary, the pandemic has had an overwhelming impact on ICU specialists. With about half the ICU physicians having symptoms of severe burnout and anxiety as well as $30 \%$ with symptoms of depression, we can consider that COVID-19 has generated a mental health emergency. The lack of knowledge and experience about the disease was most probably a source of anxiety. Clinicians ranked this burden as the most significant professional and emotional challenge when compared to non-COVID-19 patients. These mental health problems may be generated by a failure to triage appropriately, manage and make decisions for the patients and the lack of an optimal ethical climate, more than the exposure to the disease or the physician strain form the surge. Physicians follow-up, and management are warranted to assess long-term psychological outcomes of the COVID-19 outbreak and alleviate the psychological burden of the pandemic on exhausted professionals.

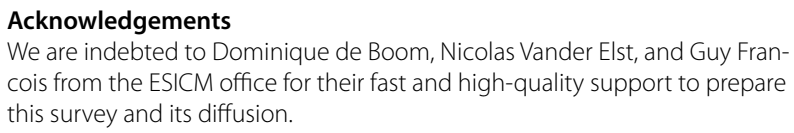

Authors' contributions

All authors contributed to the study design. All authors read and approved the final manuscript.

\section{Funding}

None.

Availability of data and materials

Fully available upon request.

Ethics approval and consent to participate

All participants agreed online to complete the survey.

Consent for publication

All participants consented.

\section{Competing interests}

Authors declare no conflict of interest in relation with this survey.

\section{Author details}

${ }^{1}$ Médecine Intensive et Réanimation, PHP, Hôpital Saint-Louis, Paris University, Paris, France. ${ }^{2}$ Department of Critical Care Medicine, Ghent University Hospital, 9000 Gent, The Netherlands. ${ }^{3}$ Shock, Organ Dysfunction, and Resuscitation Research Group (SODIR), Instituto de Investigación de Vall d'Hebron, Barcelona, Spain. ${ }^{4}$ Departmento de Medicina Intensiva, Hospital Universitario de Vall d́Hebron, Centro de Investigación Biomédica en Red (CIBER) de Enfermedades Respiratorias, Barcelona, Spain. ${ }^{5}$ Department of Medicine I, Intensive Care Unit, Medical University of Vienna, Vienna General Hospital, Vienna, Austria. ${ }^{6}$ NOVA Medical School, CHRC, New University of Lisbon, Lisbon, Portugal. ${ }^{7}$ Unidade de Cuidados Intensivos Polivalente, Hospital de São Francisco Xavier, CHLO, Estrada Do Forte Do Alto Do Duque, 1449-005 Lisbon, Portugal. ${ }^{8}$ Hellenic Army, ICU Nurse Manager General Military Hospital, Athens, Greece. ${ }^{9}$ Critical Care Center, Sabadell Hospital, University Institute Parc Taulí, Autonomous University of Barcelona, Ciberes, Barcelona, Spain. ${ }^{10}$ Department of Anesthesiology and Intensive Care, School of Medicine, Klinikum rechts der Isar, Technical University of Munich, Munich, Germany. ${ }^{11}$ School of Immunology and Microbial Science, Kings College London, London, UK. ${ }^{12}$ Guy's and St Thomas' NHS Foundation Trust, ICU Support Offices, St Thomas' Hospital, 
London, UK. ${ }^{13}$ Department of Surgical Sciences and Central Intensive Care Unit, Department of Anesthesia, Operation, and Intensive Care and Department of Anesthesiology and Intensive Care Medicine, Institute of Clinical Sciences, Sahlgrenska Academy, University of Gothenburg, Gothenburg, Sweden. ${ }^{14}$ Department of Intensive Care Medicine, Division of Anesthesiology, Intensive Care and Emergency Medicine, University Medical Center Utrecht, Utrecht University, Utrecht, The Netherlands. ${ }^{15}$ Humanitas Clinical and Research Center, Humanitas University, Milan, Italy.

Received: 2 July 2020 Accepted: 25 July 2020

Published online: 08 August 2020

\section{References}

1. Rubin EJ, Harrington DP, Hogan JW, Gatsonis C, Baden LR, Hamel MB. The urgency of care during the Covid-19 pandemic-learning as we go. N Engl J Med. 2020. https://doi.org/10.1056/nejme2015903.

2. Shang Y, Pan C, Yang X, et al. Management of critically ill patients with COVID-1 9 in ICU: statement from front-line intensive care experts in Wuhan, China. Ann Intensive Care. 2020;10(1):73. https://doi.org/10.1186/ s13613-020-00689-1.

3. Sun Q, Qiu H, Huang M, Yang Y. Lower mortality of COVID-19 by early recognition and intervention: experience from Jiangsu Province. Ann Intensive Care. 2020;10(1):33. https://doi.org/10.1186/s13613-020-00650-2.

4. Brooks SK, Webster RK, Smith LE, et al. The psychological impact of quarantine and how to reduce it: rapid review of the evidence. Lancet Lond Engl. 2020:395(10227):912-20. https://doi.org/10.1016/S0140-6736(20)30460-8.

5. Alhazzani W, Møller MH, Arabi YM, Sepsis Surviving, et al. Campaign: guidelines on the management of critically ill adults with coronavirus disease 2019 COVID-19. Intensive Care Med. 2020. https://doi.org/10.1007/ s00134-020-06022-5.

6. Murthy S, Gomersall CD, Fowler RA. Care for critically ill patients with COVID-19. JAMA. 2020. https://doi.org/10.1001/jama.2020.3633.

7. Lai J, Ma S, Wang Y, et al. Factors associated with mental health outcomes among health care workers exposed to coronavirus disease 2019. JAMA Netw Open. 2020;3(3):e203976. https://doi.org/10.1001/jamanetwor kopen.2020.3976.

8. Rossi R, Socci V, Pacitti F, et al. Mental health outcomes among frontline and second-line health care workers during the coronavirus disease 2019 (COVID-19) pandemic in Italy. JAMA Netw Open. 2020;3(5):e2010185e2010185. https://doi.org/10.1001/jamanetworkopen.2020.10185.

9. Liu CH, Zhang E, Wong GTF, Hyun S, Hahm HC. Factors associated with depression, anxiety, and PTSD symptomatology during the. Psychiatry Res. 2020;290:113172. https://doi.org/10.1016/j.psychres.2020.113172.

10. Elbay RY, Kurtulmuş A, Arpacıoğlu S, Karadere E. Depression, anxiety, stress levels of physicians and associated factors in Covid-19 pandemics. Psychiatry Res. 2020;290:113130. https://doi.org/10.1016/j.psychres.2020.113130

11. Pappa S, Ntella V, Giannakas T, Giannakoulis VG, Papoutsi E, Katsaounou P. Prevalence of depression, anxiety, and insomnia among healthcare workers during the. Brain Behav Immun. 2020. https://doi.org/10.1016/j. bbi.2020.05.026.

12. Morgantini $L A$, Naha $U$, Wang $H$, et al. Factors contributing to healthcare professional burnout during the COVID-19 pandemic: a rapid turnaround global survey. MedRxiv Prepr Serv Health Sci. 2020. https://doi. org/10.1101/2020.05.17.20101915.

13. Barello S, Palamenghi L, Graffigna G. Burnout and somatic symptoms among frontline healthcare professionals at the peak of the Italian COVID-19 pandemic. Psychiatry Res. 2020;290:113129. https://doi. org/10.1016/j.psychres.2020.113129.

14. Poncet MC, Toullic P, Papazian $L$, et al. Burnout syndrome in critical care nursing staff. Am J Respir Crit Care Med. 2007;175(7):698-704. https://doi. org/10.1164/rccm.200606-8060C.

15. Embriaco N, Azoulay E, Barrau K, et al. High level of burnout in intensivists: prevalence and associated factors. Am J Respir Crit Care Med. 2007;175(7):686-92. https://doi.org/10.1164/rccm.200608-1184OC.

16. Dewey C, Hingle S, Goelz E, Linzer M. Supporting clinicians during the COVID-19 pandemic. Ann Intern Med. 2020;172(11):752-3. https://doi. org/10.7326/M20-1033.
17. Gold JA. Covid-19: adverse mental health outcomes for healthcare workers. BMJ. 2020;369:m1815. https://doi.org/10.1136/bmj.m1815.

18. Anmella G, Fico G, Roca A, et al. Unravelling potential severe psychiatric repercussions on healthcare professionals during the COVID-19 crisis. J Affect Disord. 2020;273:422-4. https://doi.org/10.1016/j.jad.2020.05.061.

19. Zigmond AS, Snaith RP. The hospital anxiety and depression scale. Acta Psychiatr Scand. 1983;67(6):361-70. https://doi. org/10.1111/j.1600-0447.1983.tb09716.x.

20. Pochard F, Azoulay E, Chevret S, et al. Symptoms of anxiety and depression in family members of intensive care unit patients: ethical hypothesis regarding decision-making capacity. Crit Care Med. 2001;29(10):1893-7.

21. Dzeng E, Curtis JR. Understanding ethical climate, moral distress, and burnout: a novel tool and a conceptual framework. BMJ Qual Saf. 2018;27(10):766-70. https://doi.org/10.1136/bmjqs-2018-007905.

22. Sprung $C L$, Ricou $B$, Hartog CS, et al. Changes in end-of-life practices in European intensive care units from 1999 to 2016. JAMA. 2019;322(17):112. https://doi.org/10.1001/jama.2019.14608.

23. Sasangohar F, Jones SL, Masud FN, Vahidy FS, Kash BA. Provider burnout and fatigue during the COVID-19 pandemic: lessons learned from a highvolume intensive care unit. Anesth Analg. 2020. https://doi.org/10.1213/ ane.00000000000004866.

24. Joynt GM, Loo S, Taylor BL, et al. Chapter 3. Coordination and collaboration with interface units. Recommendations and standard operating procedures for intensive care unit and hospital preparations for an influenza epidemic or mass disaster. Intensive Care Med. 2010;36:S21-31. https:// doi.org/10.1007/s00134-010-1762-3.

25. White DB, Lo B. A framework for rationing ventilators and critical care beds during the COVID-19 pandemic. JAMA. 2020. https://doi. org/10.1001/jama.2020.5046.

26. Truog RD, Mitchell C, Daley GQ. The toughest triage_-allocating ventilators in a pandemic. N Engl J Med. 2020. https://doi.org/10.1056/nejmp2005689.

27. Aziz S, Arabi YM, Alhazzani W, et al. Managing ICU surge during the COVID-19 crisis: rapid guidelines. Intensive Care Med. 2020. https://doi. org/10.1007/s00134-020-06092-5.

28. van Mol MMC, Kompanje EJO, Benoit DD, Bakker J, Nijkamp MD. The prevalence of compassion fatigue and burnout among healthcare professionals in intensive care units: a systematic review. PLOS ONE. 2015;10(8):e0136955. https://doi.org/10.1371/journal.pone.0136955.

29. Merlani P, Verdon M, Businger A, Domenighetti G, Pargger H, Ricou B. Burnout in ICU caregivers: a multicenter study of factors associated to centers. Am J Respir Crit Care Med. 2011;184(10):1140-6. https://doi. org/10.1164/rccm.201101-00680C.

30. Verdon M, Merlani P, Perneger T, Ricou B. Burnout in a surgical ICU team. Intensive Care Med. 2008;34(1):152-6. https://doi.org/10.1007/s0013 4-007-0907-5.

31. Garrouste-Orgeas M, Perrin M, Soufir L, et al. The latroref study: medical errors are associated with symptoms of depression in ICU staff but not burnout or safety culture. Intensive Care Med. 2015;41(2):273-84. https:// doi.org/10.1007/s00134-014-3601-4.

32. Lederer W, Kinzl JF, Traweger C, Dosch J, Sumann G. Fully developed burnout and burnout risk in intensive care personnel at a university hospital. Anaesth Intensive Care. 2008;36(2):208-13. https://doi.org/10.1177/03100 57X0803600211.

33. Van den Bulcke B, Metaxa V, Reyners AK, et al. Ethical climate and intention to leave among critical care clinicians: an observational study in 68 intensive care units across Europe and the United States. Intensive Care Med. 2020;46(1):46-56. https://doi.org/10.1007/s00134-019-05829-1.

34. Azoulay E, Kentish-Barnes N. A 5-point strategy for improved connection with relatives of critically ill patients with COVID-19. Lancet Respir Med. 2020;8(6):e52. https://doi.org/10.1016/S2213-2600(20)30223-X.

35. Benoit DD, Jensen HI, Malmgren J, et al. Outcome in patients perceived as receiving excessive care across different ethical climates: a prospective study in 68 intensive care units in Europe and the USA. Intensive Care Med. 2018:44(7):1039-49. https://doi.org/10.1007/s00134-018-5231-8.

\section{Publisher's Note}

Springer Nature remains neutral with regard to jurisdictional claims in published maps and institutional affiliations. 